\title{
GRAMSCI Y EL PROCESO HEGEMÓNICO EDUCATIVO
}

\author{
Guillermo Miranda Camacho ${ }^{1}$
}

\begin{abstract}
"Una reforma intelectual y moral no puede dejar de estar ligada a un programa de reforma económica, o mejor, el programa de reforma económica es precisamente la manera concreta de presentarse de toda reforma intelectual y moral". Antonio Gramsci
\end{abstract}

\section{Resumen}

El presente ensayo es una aproximación hermenéutica a uno de los núcleos centrales del pensamiento de Antonio Gramsci: la construcción del proceso hegemónico educativo; también se destacan la actualidad y vigencia de su pensamiento. Para realizar esta tarea de analizar sus aportaciones, en un primer momento se hace una exploración de la interrelación del concepto de sociedad civil y su interacción dialéctica con el Estado (sociedad política). En un segundo momento, se exploran las complejas, poderosas y sutiles formas que asume la hegemonía política y cultural promovida por la clase dirigente, desde el Estado, para consolidar un consenso ideológico en tomo a su proyecto hegemónico. En un tercer momento, se exploran algunas dimensiones relativas a la participación directa del Estado en la educación, desde la perspectiva de los procesos que explican la vinculación histórica de lo político y lo educativo. Para comprender este proceso, se retoma el planteamiento gramsciano relativo a la hegemonía que se instaura en la sociedad civil en el marco de la construcción de una unidad social-cultural, analizando el concepto de intelectual orgánico y su papel en la configuración de la hegemonía social. La cuarta parte comprende un análisis de la vinculación histórica Estado-educación, desde la óptica de la articulación orgánica entre la base estructural y la superestructura ideológica y, por ende, de la construcción de un sistema ideológico. Finalmente, se realiza una aproximación a la visión gramsciana de la vinculación

1 Sociólogo y pedagogo. Profesor de la División de Educación Rural, CIDE. Universidad Nacional. (gmicl@hotmail.com). 
educación-hegemonía, se destacan su significación y su vigencia para el análisis del papel de la política educativa como proceso hegemónico en la sociedad civil.

\section{Abstract}

Hermeneutic approach to one of Antonio Gramsci's central thoughts: the construction of the hegemonic educational process. The essay points out that Gramsci's thought is still valid for modern times, and in order to analyze the contributions of his thoughts to education as hegemony, the author explores the interrelationship between the concept of civil society and its dialectic interaction with the State (political society). Likewise, the complex, powerful and subtle forms adopted by the cultural and political hegemony fostered by the ruling class, are analyzed to consolidate an ideological consensus around its hegemonic project.

The third section explores some dimensions related to the State's direct involvement in education, from the point of view of the processes that account for the historical link between the political and the educational elements. In order to explain the process, we resume Gramsci's proposal in relation to the hegemony that is established in the civil society under the construction of a socio-cultural unity and analyse the concept of organic intellectual and its role in conforming social hegemony.

Fourth, we include an analysis of the historical link State-education from the point of view of organic articulation between the structural basis and the ideological superstructure and, therefore, from the construction of an ideological system. Finally, there is an approximation to Gramsci's vision on the education-hegemony link, pinpointing its meaning and actuality for the analysis of the role played by educational politics as a hegemonic process in civil society.

\section{Palabras claves}

Hegemonía, sociedad civil, sociedad política, intelectual orgánico, consenso, unidad social-cultural, sistema hegemónico, proceso hegemónico educativo.

\section{VIGENCIA DEL PENSAMIENTO DE GRAMSCI}

\section{A 1 referirse al significado y la vigencia de las aportaciones de Antonio Gramsci, Angelo Broccoli manifiesta:}

Hoy se habla de 'imaginación sociológica' a propósito de Gramsci y de su reconstrucción de las relaciones sociales; y no sólo eso sino que algunos le reconocen inclusive el mérito de haber anticipado situaciones recientes. El hilo de esta nueva profundización habría que buscarlo en la atención gramsciana a los procesos de diferenciación y de integración de la sociedad $(1977,102)$. 
Esta afirmación pone de relieve la riqueza analítica del pensamiento gramsciano y su aporte al análisis crítico de la configuración del proceso hegemónico en la sociedad civil. No ha sido casualidad que el historiador británico Eric Hobsbawn pusiera de manifiesto que, durante la década de los ochenta, Antonio Gramsci se convirtió en el pensador italiano que más se cita en las publicaciones mundiales de humanidades y ciencias sociales (Fernández, 2001). Autores autorizados en la obra de Gramsci, como Umberto Cerroni, Norberto Bobbio, Cesare Luporini, Nicola Matteuci, María A. Macciocchi, Angelo Broccoli, Perry Anderson, Joseph W. Femia y Paul Ransom, por citar algunos, coinciden, no obstante sus particulares visiones, en la importancia capital de su contribución en el análisis sociopolítico de las formas complejas en que se manifiesta el poder, como hegemonía ideológica de alcance cultural en formaciones sociales concretas. A Gramsci se le atribuye el mérito de haber brindado aportes sustantivos en el análisis de la inmensa cantidad de matices que pueden adquirir las distintas formas de dominación desde la esfera de lo ideológico. Por ello, se le reconoce como el gran teórico de la hegemonía.

La vigencia del pensamiento gramsciano se manifiesta en la utilización de sus aportes en el ámbito de la sociología de la educación, particularmente desde la visión de la vinculación del sistema educativo y las prácticas educativas con la reproducción económica y cultural. En efecto, el vigoroso resurgimiento de esta corriente reconocida en los círculos académicos, que aglutina una importante cantidad de teóricos y proponentes de alternativas pedagógicas, identificados como neogramscianos, es una muestra ostensible del reconocimiento del valor teórico, heurístico y hermenéutico de la obra gramsciana. Pero, en especial, de la plena vigencia y validez científica de su contribución al análisis de la construcción de los sistemas hegemónicos, del papel de la institución escolar en esos procesos y, en particular de la interacción dialéctica entre conocimiento, currículo y poder en el escenario educativo actual. Es interesante hacer notar que en la tradición anglosajona del desarrollo científico-social, es donde en los últimos años se puede encontrar una de las más conspicuas expresiones de esta tendencia. Ciertamente, autores como Raymond Williams, Roger Dale, James W. Apple, Henry Giroux, Rachel Sharp, constituyen representativas expresiones de las aplicaciones en investigación desde una sociología crítica de la educación, de la política educativa y de las reformas educativas y curriculares. La vigencia del pensamiento gramsciano también se evidencia en la teoría sustantiva para el desarrollo hermenéutico crítico de la producción cultural y de las posiciones de resistencia cultural y educativa en los Estados Unidos; la teoría y la práctica que se asumen a partir de la relación entre resistencia educativa y pedagogía crítica con las Teorías de la resistencia representan, en efecto, una muestra de la actualidad del pensamiento de Gramsci. 
A nuestro entender, su obra presenta, además de su visión futurista respecto del desarrollo de la sociedad capitalista, una unidad teórica de una enorme riqueza, por su potencial heurístico para el estudio de procesos de configuración hegemónica, política y cultural y, por lo tanto, para la construcción de visiones interpretativas relativas al examen crítico de la sociedad global. La centralidad del tema pedagógico en la obra de Gramsci radica, en efecto, en la significación que le confiere a la relación pedagógica y la elaboración cultural en el contexto de las acciones que las clases dirigentes acometen para mantener su hegemonía política y cultural en la sociedad civil. Este es el aspecto medular por el que pone su énfasis interpretativo (excesivo al entender de algunos, por ejemplo, la crítica de Althusser) en el nivel de la superestructura. "Gramsci no es ciertamente el teórico marxista de la sociedad industrial, pero constituye - dice Broccoli- un pasaje obligado para repensar críticamente una fase del desarrollo de esa sociedad" $(1977,17)$. No hay duda de su alejamiento de toda ortodoxia marxista, negando automatismos de índoles mecanicistas o dogmáticas, en las interrelaciones entre superestructura y estructura en toda forma de dominación.

Desde nuestro punto de vista, consideramos de acuerdo con Angelo Broccoli, que su mayor contribución es,

...haber intuido que el problema pedagógico o es el problema de una estructura social en su conjunto, en toda la gama más o menos vasta de sus articulaciones, o bien, es una estéril ejercitación de expertos en esta o en aquella técnica, pero incapaces de promover el desarrollo efectivo de las masas como de los individuos $(1977,19)$.

He aquí la importancia del concepto de hegemonía como problema pedagógico, en la cual hay que reconocer un esfuerzo de un enorme significado histórico en la elaboración de una teoría de la comunicación, así como de recoger la diversidad de los cambios de la condición económica y la concepción del mundo - por caminos originales y de particular hondura analítica y crítica-, vinculados a la formulación de las políticas educativas en las formaciones sociales capitalistas.

\section{HEGEMONÍA Y SOCIEDAD CIVIL}

En lo referente al establecimiento de una conciencia colectiva homogénea alrededor de los objetivos políticos de la clase dirigente en la sociedad civil, Gramsci pone de manifiesto el problema de las dos dimensiones de la 
hegemonía: la cultural y la política. Un aporte fundamental en la comprensión dialéctica de las relaciones de fuerza entre los diferentes actores de la sociedad civil ha sido su tesis e interpretaciones sobre el carácter cultural que complementa e integra la hegemonía política en el contexto de la sociedad civil. Por consiguiente, esta categoría se constituye en un concepto nuclear para la comprensión de las manifestaciones ideológicas y la dinámica de poder en la estructura social. Con Gramsci, el concepto de sociedad civil evoluciona en una dirección distinta, apartándose de la ortodoxia hegeliana y marxista, aunque los referentes epistemológicos de este concepto estén en ambos sistemas filosóficos (Portelli, 1980; Femia, 1987; Ransom, 1992). En su obra de madurez, la definió así:

Por ahora se pueden fijar dos grandes planos superestructurales, el que se puede llamar de la 'sociedad civil', que está formado por el conjunto de los organismos vulgarmente llamados 'privados' y el de la 'sociedad política o estado' que corresponde a la función de 'hegemonía' que el grupo dominante ejerce en toda la sociedad y la del 'dominio directo'o de comando que se expresa en el estado y en el 'gobierno jurídico'. Estas funciones son precisamente organizativas y conectivas (IO, 1975, 17) ${ }^{2}$.

Acerca de la concepción gramsciana de sociedad civil, Norberto Bobbio (1982) explica que mientras Marx la determina en la esfera de las relaciones económicas, para Gramsci corresponde al momento de la superestructura, en particular al de la hegemonía como dirección espiritual y cultural y abarca todo el conjunto de las relaciones ideológico-culturales. Esta distinción es importante, porque permite comprender que el dominio, como expresión del poder político que las clases dirigentes ejercen por medio del Estado, es un fenómeno no sólo de fuerza, sino que se da también a través del consenso. Si bien el Estado y el sistema político en general tienen necesidad de un aparato coactivo, también es cierto que requieren de una organización institucional, cuya función primordial es la transmisión y, por ende, la legitimación de valores dominantes (periódicos, sistema escolar, editoriales, organismos culturales).

Las clases dirigentes aseguran su hegemonía política no sólo a través de medios coercitivos, sino también difundiendo su visión del mundo: su filosofía, su ética y moral, su cultura, su sentido común. De esta manera, el ejercicio del poder no solamente es presión de las relaciones económicas dominantes, sino que está dirigido a difundir ciertos valores determinados por esas mismas

\footnotetext{
$\overline{2}$ Las obras de Gramsci están indicadas en el texto con siglas. Véase la bibliografía.
} 
relaciones y por los compromisos con otras fuerzas sociales con las que comparte (o aparenta compartir) ese poder (Macciocchi, 1980). Esta consideración nos permite comprender la dialéctica de la relación estructura (base social y económica)/superestructura (sistema ideológico) en el bloque histórico desde el punto de vista de la relación acción/conciencia, según la cual,

...cuando la acción de las masas está en oposición con el poder dominante, su conciencia, es decir, su propia manera de pensar, sigue marcada por la hegemonía ideológica de las fuerzas políticas adversas, pues las masas han sido educadas no sólo con una mentalidad opuesta a sus propios intereses fundamentales, sino también a su propia praxis (Macciocchi, 1980, 153).

La estructura y la superestructura forman la síntesis de lo que Gramsci denominó fuerzas materiales e ideologías, que encuentran su posibilidad de acción en el marco de la estructura global del bloque histórico por medio de la hegemonía, categoría cardinal que incorpora en su connotación, la cohesión del bloque histórico a partir de la visión del mundo (como superestructura) y la capacidad de las clases dirigentes de presentar programas de acción concretos frente a la realidad social en el plano estructural.

Uno de los aportes más importante de Gramsci a la teoría del Estado es el concepto de sociedad civil, lugar en el cual la clase dirigente mantiene su liderazgo ideológico y su hegemonía. Con esto se demuestra la complejidad, la articulación y la relativa independencia que tienen las instituciones, las organizaciones, las formas de conciencia, el funcionamiento del sistema económico, las prácticas sociales y la configuración de los sistemas simbólicos de representación de la realidad; asimismo, la relativa independencia que poseen las instituciones, las organizaciones, en fin, todas las formas en que se manifiesta el poder de la clase dirigente para mantener su control político y cultural.

Otra decidida contribución a la hermenéutica de los procesos de dominación está referida a los momentos de fuerza y consenso. Estos extremos representan una unidad dialéctica y hay un momento superestructural, en el cual la clase dirigente mantiene su hegemonía a través de su sistema, es decir, del complejo de sus aparatos ideológicos. La sociedad civil representa un escenario que envuelve la esfera de acción del(la) ciudadano(a) desde su infancia en el universo escolar y más tarde su participación en todas las organizaciones privadas en que se integra; "esta prisión de mil ventanas simboliza el reinado de la hegemonía cuya fuerza reside menos en la coerción que en el hecho de que sus barrotes son tanto más eficaces cuanto que son menos invisibles" (Macciocchi, 1980, 155). 
Gramsci define la sociedad civil como hegemonía política y cultural de un grupo social sobre el conjunto de la sociedad y, a la vez, como contenido ético del Estado formado por "el conjunto de los organismos vulgarmente llamados privados" (IO, 1975, 17). La sociedad política representa, por su parte, el ejercicio de la coacción, vale decir, de la conservación por medio de la violencia del statu quo, no sólo por la vía militar o policial, sino también por la vía jurídica: coacción legal.

La sociedad política cumple dos funciones en el interior del bloque histórico: la primera es de control de la clase fundamental sobre los grupos sociales y clases subordinadas, que en algún momento entran en contradicción a partir del desarrollo de las relaciones económicas y sociales. El recurso de la coacción se realiza en el marco jurídico establecido para la dominación. La segunda corresponde a situaciones más excepcionales que Gramsci llamó crisis orgánicas, situaciones históricas particulares, en las cuales la clase dirigente pierde su control sobre la sociedad civil, por lo que recurre a la sociedad política (Portelli, 1980, 29). De lo anterior se desprende una consideración de particular importancia en cuanto a la función de la sociedad política: el papel coercitivo no sólo se circunscribe al campo militar o policial, sino que a través del gobierno jurídico se da una coacción que es de carácter legal.

El papel ideológico y dirigente, que tiene lugar en el ámbito del ejercicio del poder, se explica por la dialéctica sociedad civil/sociedad política. Para comprender esta relación, es importante hacer algunos comentarios. Gramsci distingue, para efectos analíticos, dos concepciones de Estado. Una de carácter heurístico: el momento en que identifica la sociedad política con el Estado (en sentido restringido) para destacar la preeminencia de su papel coercitivo, frente a las funciones ideológicas y educativas propias de la sociedad civil. El aporte teórico de Gramsci en el análisis del papel del Estado, en este sentido, conduce al conocimiento de su papel de aparato coercitivo y de dictadura al servicio de la clase dirigente, en el sometimiento a la estructura de producción y a la economía en un momento determinado. Otra de carácter orgánico, que concibe el Estado en sentido amplio, reunificando la sociedad civil y la sociedad política, a partir de la forma en que ambas estructuras se identifican en la realidad.

El aporte de Gramsci radica en interpretar el equilibrio entre el papel de dominación y el de hegemonía ejercida a través de organizaciones, tales como la escuela, la Iglesia, etc., en la sociedad civil, en la cual los intelectuales realizan su tarea. La función del Estado, por consiguiente, no sólo es de aparato represivo y de mando en resguardo de los intereses económicos de la clase dirigente, sino también de mediador entre esos intereses y los de las clases 
subordinadas. En consecuencia, el Estado representa la unidad de los objetivos políticos y económicos logrados por medio de la hegemonía ideológica y cultural. Para la articulación de un bloque de fuerzas, el Estado trabaja en la formación de una voluntad colectiva nacional (unidad social-cultural), representando las ideas de las clases dirigentes como valores universales, es decir, creando una unidad intelectual y moral (Macciocchi, 1980).

Esta visión logró un mayor entendimiento de la forma en que se realiza la hegemonía en el seno de la sociedad civil en la tradición marxista, que consiste en la diferenciación-complementación de los tipos de direcciones que las clases dirigentes le confieren al proceso hegemónico, tanto en el ámbito de la acción del Estado, dirección política (aparato coercitivo), como en el de la dirección cultural (hegemonía ideológica a través de la sociedad civil). En estos elementos consiste su carácter dirigente. Así, la dialéctica de la superestructura comprende dos momentos antagónicos que se integran como ex presión del poder de las clases dirigentes. El momento de la hegemonía (función de la sociedad civil) y el momento de la dominación (función de la sociedad política). En estos aspectos radica el carácter organizativo y conectivo que Gramsci le atribuyó a la relación entre la sociedad política y la sociedad civil. Broccoli (1977) apunta, que el tema de la unidad social-cultural es una constante en el curso de toda la obra gramsciana.

Portelli afirma, a este respecto, que la división entre la sociedad política y la civil es de naturaleza heurística y funcional, y que en la práctica corresponden a dos dimensiones de un mismo proceso social, en el cual establecen una interacción dialéctica. Asimismo, aclara que:

El problema de las relaciones entre sociedad civil y sociedad política es esencialmente una cuestión metodológica: son dos aspectos de la hegemonía de la clase dominante. No obstante, su distinción es esencial. El hecho de que tal o cual organización dependa de una u otra sociedad importa menos que el rol respectivo de estos dos momentos de la superestructura de un periodo histórico y en un país determinado $(1980,35)^{3}$.

De este pasaje se desprende la importancia fundamental de la función que el concepto de hegemonía realiza en la sociedad civil. La relación entre la

\footnotetext{
${ }^{3}$ Portelli aclara: "El esquema dentro del cual Gramsci razona es, y él mismo lo reconoce, el de un periodo determinado: el del Estado liberal o Estado gendarme" (1980, 32-33). Gramsci demostró a través de su obra ser un profundo conocedor de la cultura moderna y el Estado liberal moderno europeo de su tiempo.
} 
sociedad civil y la sociedad política no se reduce a una simple relación funcional entre ambas; antes bien, se trata de una relación dialéctica que hace que entre estas estructuras regionales tengan lugar cambios recíprocos.

\section{Sociedad civil e ideología}

Destacar el papel de la sociedad civil, como estructura regional, significa destacar el papel del campo básico de acción de la ideología. Desde esta óptica, y siguiendo el esquema de análisis de Portelli (1980, 17-15), la dinámica ideológica que tiene lugar en la sociedad civil comprende al menos tres dimensiones, que en la práctica integran una realidad única y compleja. Primera, como ideología de la clase dirigente, abarca todas las ramas de la ideología: artes, ciencias, economía, derecho, etc. Según Gramsci, toda concepción del mundo o filosofía que se haya convertido en una 'religión' o una 'fe', es decir, que sus planteamientos teóricos generen una actividad práctica y una voluntad, está implícita en toda la esfera de las actividades de la sociedad. Por ende, toda actividad de alguna manera es la expresión de una concepción del mundo: "una ideología que se podría decir, si al térnino ideología se le diera el significado más alto de concepción del mundo que se manifiesta implícitamente en el arte, en el derecho, en la actividad económica, en todas las manifestaciones de la vida individual y colectiva" (MS, 1975, 16). De aquí surge el problema fundamental que debe afrontar la clase dirigente de conservar la unidad ideológica de todo el bloque social "que precisamente es cimentado y unificado por esta ideología” (MS, 1975, 16). En virtud de esta unicidad, las ideologías orgánicas, que operan desde el nivel superestructural, crean cada vez más capas de intelectuales que se especializan en algún aspecto particular de la ideología de la clase dirigente. En síntesis, las ideologías orgánicas son partes integrantes de un todo: la concepción del mundo (sistema ideológico unificado por la fílosofía) de la clase dirigente.

Segunda, es una concepción del mundo difundida por la clase dirigente a todas las capas sociales. Analíticamente comprende, según el planteamiento de Gramsci, a diferentes grados cualitativos diferenciados de concreción de la ideología: desde la filosofía (la ideología en su sentido más acabado), pasando por la religión y el sentido común, hasta el folclore (fragmentos dispersos de ideologías pertenecientes a la cultura popular). ¿A cuáles razones obedece esta clasificación? En especial, a un criterio de unidad y complejidad del conjunto cultural. La existencia de diferentes niveles heterogéneos de ideología se corresponde con las necesidades históricas derivadas de los problemas planteados por las estructuras sociales, hecho en el cual radica el interés de Gramsci 
por estudiarlas. Siendo la manifestación cultural más racional y profunda, la filosofía representa la concepción del mundo de la clase fundamental; por ello define su lugar y función en un momento del desarrollo histórico y social. Elaborada por los intelectuales, es la piedra angular de la hegemonía: el estadio de una mayor jerarquía en el sistema hegemónico. Una de sus características esenciales es su alto grado de coherencia, por lo que constituye el marco de referencia de todo el sistema ideológico:

Que una masa de hombres sea llevada a pensar coherentemente y en forma unitaria la realidad presente, es un hecho 'filosófico' mucho más importante y 'original' que el hallazgo, por parte de un 'genio' filosófico, de una nueva verdad que sea patrimonio de pequeños grupos de intelectuales (MS, 1975, 13).

Otro aspecto fundamental de la filosofía es su historicidad; para Gramsci la filosofía de una época histórica es la historia de la época misma, esto es, la manera en que el grupo dirigente ha manejado en el pasado su poder de crear y difundir su ideología. A este respecto afirmaba que la filosofía y la historia forman un bloque.

Tercera, como dirección ideológica de la sociedad, se articula en tres ámbitos: la ideología propiamente, la estructura ideológica integrada por las organizaciones que crean y difunden la ideología, y el material ideológico. Dos conceptos claves muestran la forma en que se articula la organización para el logro de la unidad ideológica de la sociedad: el de estructura ideológica y el de material ideológico. Gramsci definió la estructura ideológica como "la organización material dedicada a mantener, defender y desarrollar el 'frente' teórico o ideológico" (PP, 1975, 215). Este concepto agrupa las organizaciones cuya función hegemónica se traduce en producción y difusión de la ideología. El papel de producción corresponde a la universidad, la academia y los centros de investigación en general. En la difusión intervienen la Iglesia, el aparato escolar, los órganos de prensa y las editoriales. Los diferentes canales de difusión de la ideología corresponden a la gradación de la ideología en la sociedad civil, su importancia está estrechamente ligada a las necesidades que la sociedad presente como parte de su desarrollo histórico y la situación concreta de la realidad estructural. Gramsci le otorga un papel preponderante al aparato hegemónico escolar, por ser el que abarca un radio de acción más amplio en el proceso de difundir la ideología. En esta función participan la Iglesia, la universidad y la academia.

El resaltar el papel hegemónico de la educación constituye una de las contribuciones más importantes de Gramsci a la teoría de la ideología. Hay que 
considerar, asimismo, los medios de comunicación de una amplia difusión, que Gramsci agrupó bajo el concepto de material ideológico, tales como la prensa, la radio, el cine, el teatro; también incluyó en los canales de difusión la arquitectura y el urbanismo ${ }^{4}$.

\section{LA VINCULACIÓN HISTÓRICA ESTADO Y EDUCACIÓN: EL PAPEL DE LOS INTELECTUALES}

El análisis de la participación directa del Estado en la educación lleva a formular la siguiente interrogante: ¿Cuáles son, desde la perspectiva analítica de Gramsci, los principales procesos que explican la vinculación histórica de lo político y lo educativo? Para responder a esta pregunta, retomaremos el planteamiento gramsciano relativo a la hegemonía que se realiza en la sociedad civil en el marco de la unidad social-cultural y analizaremos el concepto de intelectual y sus funciones en la configuración de la hegemonía social; esto nos permitirá, posteriormente, abordar la articulación Estado-educación y la configuración del proceso hegemónico educativo.

\section{Los intelectuales: sus funciones orgánicas}

Una categoría fundamental en el conjunto del pensamiento gramsciano es la de los intelectuales. El espacio de acción de los intelectuales, como categoría social, es la sociedad civil (Manacorda, 1987, 52); ahí donde cumplen su función de articular la hegemonía desde las organizaciones que la integran (Iglesia, sindicatos, escuela, entre otras). Los intelectuales representan una categoría orgánica que toda clase dirigente crea, para desarrollar una conciencia de sí y para imponerla a las clases subalternas.

¿Cómo distinguir y caracterizar a los intelectuales y sus actividades de los demás grupos sociales? La clave está en no incurrir en el error de realizar la distinción en las mismas actividades intelectuales, en vez de hacerlo en el conjunto general del sistema de relaciones (incluidas las económicas) en que tales actividades (y, por lo tanto, los grupos que las representan) tienen lugar. Siendo así, el papel sociopolítico y las funciones se definen en el conjunto de relaciones sociales y hace que exista socialmente una diferenciación-distinción que se establece por la ubicación y función de la actividad que se desarrolla en el

\footnotetext{
${ }^{4}$ Posteriormente, con el avance tecnológico aparecieron la televisión (como un medio de comunicación masiva) y la industria publicitaria. En la actualidad habría que incluir los medios que utilizan las tecnologías de la información y la comunicación (como es el caso de la red Internet), en el contexto de la emergencia de la llamada sociedad de la información.
} 
sistema de relaciones sociales. El ejemplo al que recurre Gramsci es el del empresario, que desarrolla funciones intelectuales cualificadas, aunque la naturaleza de estas y su inserción en las relaciones sociales de producción se caracterizan por su posición en la industria. Este principio lleva a Gramsci a aclarar que: "Todos los hombres son intelectuales, podría decirse por tanto; mas no todos los hombres tienen en la sociedad la función de intelectuales" (AP, 1985, 59-60). Más aún, afirma que no hay actividad humana que se sustraiga de la actividad intelectual:

(...) todo ser humano desarrolla fuera de su profesión cualquier actividad intelectual, es decir, es un 'filósofo', un artista, un hombre de gusto, participa de una concepción del mundo, tiene una línea consciente de conducta moral, contribuye, por tanto a sostener y a modificar una concepción del mundo, esto es, a suscitar nuevos modos de pensar (AP, 1985, 61).

Acerca de la autonomía e independencia o pertenencia a un determinado grupo social, Gramsci explica que el proceso histórico de formación de las distintas categorías de intelectuales ha dado lugar a dos manifestaciones ${ }^{5}$.

La primera se fundamenta en este supuesto: cada grupo social, al nacer a una función esencial en el mundo de la producción económica, crea una o varias castas de intelectuales, con el propósito de darle coherencia, homogeneidad y conciencia a esa función. Esto ocurre en los campos social, económico, cultural y político. Es claro encontrar en esta explicación, la lógica de la racionalidad instrumental, social y económica que ha caracterizado el pensamiento modernista, aplicado al sistema productivo. La relación entre la estructura y la superestructura posee, según Gramsci, un carácter orgánico que es producto del desarrollo histórico. Por ello, considera que sólo debe tomarse en cuenta las superestructuras históricamente orgánicas, esto es, las que son necesarias a una determinada estructura. ¿En qué consiste esa organicidad? Por una parte, en su permanencia, por lo que es preciso distinguir los movimientos orgánicos permanentes de los que no lo son. Por otra, la función en la organización de la estructura que históricamente es necesaria para organizar las masas humanas. Este marco interpretativo es el que hace posible definir el papel de los intelectuales y su categorización en el seno de la sociedad civil. En consecuencia, el carácter orgánico del vínculo entre estructura y superestructura determina las

\footnotetext{
5 Ambas manifestaciones son, a nuestro juicio, ejemplos representativos de la valiosa contribución de Gramsci al formular, con clara visión prospectiva. algunos procesos de integración y diferenciación social y prácticas sociales fundamentales, que se manifestarán ostensiblemente en la organización social y económica del capitalismo avanzado.
} 
capas de intelectuales (que al mismo tiempo son un reflejo de aquellas) y su función es propiciar esa articulación orgánica. Por consiguiente, los intelectuales son una capa social ligada a la estructura en el campo económico, encargada de conferirle homogeneidad y direccionalidad al bloque histórico(Portelli, 1980, 94-95).

Gramsci recurre, para fines explicativos, al ejemplo del empresario que "representa una elaboración superior, ya caracterizada por una cierta capacidad dirigente y técnica (es decir intelectual)"; menciona lo siguiente:

Si no todos los empresarios, al menos una élite debe poseer una capacidad de organización de la sociedad en general, con todo su complejo organismo de servicios, hasta el organismo estatal, por la necesidad de crear las condiciones más favorables a la expansión de su propia clase -o por lo menos debe tener la capacidad de elegir a sus 'delegados' (empleados especializados) a los que confiar esta actividadorganizativa de las relaciones generales de la empresa. Puede observarse que los intelectuales 'orgánicos' que cada nueva clase crea consigo 'especializaciones' de aspectos parciales de la actividad primitiva del tipo social nuevo que ha sacado a relucir la nueva clase (AP, 1985, 56-57).

Es interesante observar que este autor anticipa los fundamentos que constituirán la interrelación entre dos procesos concomitantes: el proceso de complejidad creciente que ha caracterizado la modernización capitalista (cuya racionalidad instrumental ha permeado todos los órdenes de la sociedad civil e incluso al mismo Estado) y la aparición de esa categoría de intelectuales orgánicos (técnicos sociales), que han asumido como función social la racionalización y legitimación de ese orden impuesto. Es plausible encontrar en este análisis los fundamentos sociohistóricos que explican el origen de la tecnocracia moderna, que gravita alrededor de las esferas pública y privada de las sociedades modernas y la irrupción en el plano internacional (en el periodo de posguerra), de categorías privilegiadas de tecnócratas al servicio de los organismos internacionales y las grandes corporaciones del capitalismo transnacionalizado.

La segunda manifestación en que se expresa la aparición de los intelectuales parte de esta tesis: cada grupo social al emerger a la historia a partir de la estructura económica precedente, como parte de su desarrollo estructural, ha encontrado categorías de intelectuales preexistentes que se constituyen en representantes de una continuidad histórica ininterrumpida hasta con los más complicados y radicales cambios: los intelectuales tradicionales ${ }^{6}$. Este tipo de

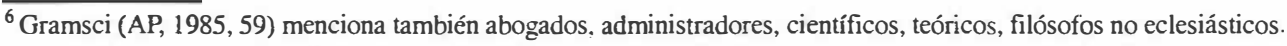


intelectuales con "espíritu de cuerpo, su ininterrumpida continuidad histórica y su cualificación"; por esto, se consideran independientes y autónomos del grupo dominante y se atribuyen características propias. Gramsci recurre al ejemplo de los eclesiásticos. Portelli $(1980,103)$ argumenta que el enfrentamiento entre los intelectuales orgánicos de la burguesía con el clero (intelectuales tradicionales) fue en realidad un enfrentamiento por la hegemonía del bloque histórico.

Respecto de estos intelectuales, Ransom resalta la aparente neutralidad con que ejercen sus funciones:

Esta 'continuidad histórica' tiene tanto una forma material como ideológica. En el caso de esta última, debería ser enfatizada la considerable influencia ejercida por las instituciones políticas y culturales incluyendo en particular los sistemas democrático, legal y educativo, que ostentan directamente el soporte de los intereses del grupo dominante. Hasta el punto que muchas veces los grupos intelectuales ayudan a la permanencia de estas instituciones, pero su aparente neutralidad puede ser más aparente que real. De modo parecido, en el campo ideológico, el grupo dominante tratará de presentar estas instituciones como si fueran de algún modo parte inevitable de la estructura de la sociedad $(1992,193)$.

Dicha función ha sido asumida históricamente por distintos grupos de intelectuales tradicionales ${ }^{8}$. Es interesante poner de relieve que este tipo de intelectuales corresponde a los conservadores; Gramsci anticipa el desarrollo teórico ulterior relativo al conservadurismo tan en boga en la actualidad, a propósito de la alianza entre neoliberales y neoconservadores: la Alianza de la Nueva Derecha (Miranda, 2004). Esto merece que realicemos una pequeña incursión en este tema por su actualidad.

Respecto de los conservadores, Eccleshall $(1993,84)$ señala que desde el siglo XIV el adjetivo de conservador ha denotado una tendencia a preservar o mantener algo intacto, y no fue sino hasta el siglo XIX cuando, tanto en Europa como en Estados Unidos, se asoció ese término con un conjunto de principios políticos. El significado de conservadurismo ha estado ligado a la tradición, al repudio, al cambio social, al apego por las reliquias del pasado y por posiciones reaccionarias que se aferran a las anticuadas prácticas sociales.

\footnotetext{
7 Traducción libre del inglés por el autor.

8 Es plausible, por consiguiente, encontrar una relación de continuidad histórica de esa función tradicional, que se extiende hasta los conservadores, y que se manifiesta en la sociedad neoliberal en grupos sociales como los conservadores de nuevo cuño o neoconservadores (entre otros).
} 
Por su parte, Dubiel indica que el neoconservadurismo, cuyo origen tuvo lugar fundamentalmente en la década de 1950, más que una teoría (en el sentido científico de la acepción) es una doctrina social orientada para la solución de los problemas políticos. Como doctrina de reacción: "Moraliza (...) argumentos de la economía política neoliberal, de la sociobiología y de la genética humana, de la crítica al marxismo positivista, de la crítica cultural conservadora y de la teoría elitista de la democracia para la defensa 'política' de una racionalidad 'liberal' de las sociedades occidentales percibida como amenazada" (1993, 6-7). Es interesante observar que, en los planteamientos discursivos, académicos o políticos de los ideólogos o políticos neoconservadores, la moralidad, en efecto, se torna en un instrumento de racionalización de sus tesis o prácticas políticas. (Esta racionalización ideológica se pone en clara evidencia en las actuales tesis educativas neoliberales). Es recurrente su invocación o apelación a valores o tendencias, justificadas como buenas o necesarias de manera explícita o implícita, para justificar su pensamiento o acciones gubernamentales ${ }^{9}$.

Los(as) nuevos(as) intelectuales tradicionales de corte neoconservador ejercen, independientemente del ámbito en que realicen su función, una decidida contribución a la consolidación y mantenimiento de la sociedad neoliberal. Pero esa contribución está de manera permanente condicionada al hecho de que no se produzcan desvaríos de radicalización liberal, que representen una afrenta a los valores, tradiciones o expresiones del pasado que consideran socialmente necesarios y, por lo tanto, que están en la base de sus tesis doctrinales. Para encubrir sus intereses reales, los intelectuales tradicionales disfrazan, como lo señala Ramson (1992), sus posiciones y actividades con un velo de aparente neutralidad, para mantener las instituciones sociales que valoran como necesarias. Esto lo logran al crear la impresión de que su visión del mundo es natural o inevitable.

La política educativa en la actual sociedad neoliberal no se ha escapado del influjo doctrinal y político de los políticos e ideólogos del neoconservadurismo. Un ejemplo es la composición de la Nueva Derecha (y sus intelectuales

\footnotetext{
${ }^{9}$ Baste mencionar algunos ejemplos representativos de dirigentes políticos como Ronald Reagan, Margaret Thatcher, Helmut Köll (con el giro político neoliberal que le confirió a su gobierno) y el expresidente del gobierno español, José María Aznar, que se caracterizó por ejercer prácticas políticas de orientación neoliberal y neoconservadoras, asumiendo un claro estilo neoautoritario frente a las reivindicaciones sociales de distintos sectores y grupos de la sociedad civil española. Su alianza internacional con los gobiemos de Estados Unidos e Inglaterra frente a los conflictos internacionales, principalmente con la intervención de Iraq, pone de relieve el carácter internacional de la Alianza de la Nueva Derecha. Asimismo, promovió un protagonismo político en el ámbito internacional, con el liderazgo de los partidos de centro-derecha. En el ámbito académico, ejemplos representativos son los casos de Daniel Bell y el de Peter Berger, dos de los teóricos neoconservadores más influyentes en los círculos académicos sociológicos e intelectuales de los Estados Unidos.
} 
aliados), la alianza estratégica entre los neoliberales y los neoconservadores, cuyas acciones, que ejercen como clases dirigentes, fluctúan en toda la gama de un abanico de posiciones: desde el neoautoritarismo hasta ciertas posturas, no exentas de cierto eclecticismo político, como la llamada Tercera Vía propuesta por el sociólogo británico Anthony Giddens; ideología política que ha asumido posiciones híbridas u oscilantes entre la socialdemocracia y el neoliberalismo ${ }^{10}$.

\section{Los intelectuales y la articulación orgánica estructura-superestructura}

La distinción entre intelectuales y no intelectuales, en la visión gramsciana, se basa no sólo en su función social de la categoría profesional de los(as) intelectuales, sino también en el peso de la naturaleza en que gravita la actividad específica profesional: trabajo intelectual o trabajo físico. Al referirse a la creación de una nueva casta intelectual, Gramsci argumenta que el problema consiste en:

(...) elaborar críticamente la actividad intelectual que existe en todos en cierto grado de desarrollo, modificando su relación con el esfuerzo muscular-nervioso hacia un nuevo equilibrio y consiguiendo que el mismo esfuerzo muscular-nervioso, en cuanto elemento de actividad práctica general, que innova perpetuamente el mundo fisico y social, devenga en fundamento de una nueva e integral concepción del mundo (AP, 1985, 61).

Esta consideración sirve de fundamento para explicar la formación histórica de la función intelectual, y de una categoría especial de intelectuales, que surge a partir de una conexión con las clases sociales fundamentales, las cuales erigen en sus representantes: los(as) intelectuales orgánicos(as). Gramsci describe este proceso en los siguientes términos:

Se forman asi históricamente categorías especializadas para el ejercicio de la función intelectual; se forman en conexión con todos los grupos sociales pero especialmente con los grupos sociales más importantes, y experimentan elaboraciones más extensas y complejas en conexión con el grupo social dominante (AP, 1985, 62).

En este contexto, se definen las funciones de los(as) intelectuales, que adquieren su organicidad y vinculación con las clases dirigentes, mediante

\footnotetext{
${ }^{10}$ En nuestra opinión uno de los críticos más acertados de la modernidad, asesor del gobiemo laborista del primer ministro Blair. Sin duda, Giddens es uno de los sociólogos británicos de mayor peso en la actualidad.
} 
la articulación de la hegemonía social y el gobierno político. Belligni apunta que en el campo de la hegemonía es donde tiene lugar "la acción orientada ideológicamente, cuyas instituciones de educación y de persuasión son los instrumentos de la dirección y transmisión del consenso" $(1982,774)$. De ahí que sus funciones intelectuales sean organizativas y conectivas, para asegurar a través del consenso, el ejercicio de las funciones subalternas en la sociedad civil, que persigue establecer la clase fundamental desde el gobierno político. Gramsci plantea que la escala de calificaciones que se presentan en este proceso y las funciones que oscilan desde la hegemonía social al dominio directo estatal definen una escala de ocupaciones que amplían la magnitud del concepto de intelectual. Por esto, afirma que en el mundo actual, la categoría de intelectuales, así entendida, se ha ampliado de modo inaudito, y responde tanto a las necesidades políticas del grupo social fundamental dominante, como a las necesidades del sistema productivo. Los(as) intelectuales orgánicos(as), como lo explica Eagleton (1997), siguiendo el planteamiento de Gramsci, son producto de una clase social emergente y su principal papel es conferirle a esas clases una autoconciencia homogénea en ámbitos como la política, la economía y la cultura. Por ello, abarca no sólo los(as) filósofos(as) sino los(as) activistas, técnicos industriales, políticos, especialistas en derecho, en economía política, etc. Representan un grupo organizador, constructor, disuador constante que al participar en forma activa en la vida social contribuyen a articular teóricamente las corrientes políticas positivas que se interrelacionan en ese escenario.

\section{MODERNIDAD CAPITALISTA Y ESTADO: EL ORIGEN DEL PROCESO HEGEMÓNICO EDUCATIVO}

Para comprender el origen del proceso hegemónico educativo, analizaremos brevemente el marco de referencia en que tiene lugar la vinculación entre el sistema educativo y el sistema productivo capitalista.

En la sociedad capitalista, los factores que determinan históricamente la articulación orgánica de la función educativa y la organización del sistema escolar con el sistema productivo se basan en dos procesos.Por una parte, la estatización de la función educativa ha constituido, como ya lo expresamos de acuerdo con Portelli (1980), una respuesta impulsada por las clases políticas desde el Estado ante la necesidad de intervenir en la elevación de calificar (a distintos niveles) la fuerza de trabajo; este proceso se realiza en el marco de la configuración del Estado capitalista ${ }^{11}$. Por la otra, al proceso de transferencia

$\overline{11}$ Tanto en su versión del capitalismo regulado como del capitalismo global. Cfr. Miranda (2004). 
del carácter contradictorio de la producción excedentaria de recursos humanos, con distintos grados de cualificación al sistema educativo. Por consiguiente, esta contradicción se transfiere al sistema educativo "con tanta más fuerza cuanto más se recurre a él como lugar de almacenamiento, canalización y empleo de esos recursos" (García, 1991, 143).

Esta problemática del excedente ha venido adquiriendo dimensiones mayores relacionadas con la reestructuración del capital en las crisis de acumulación. Así, por ejemplo, vemos que en la actualidad el desempleo, el aumento en el número de quiebras, la degradación de los niveles de vida de las capas sociales de menor ingreso, la desarticulación de las estructuras del salario social, la quiebra del movimiento social, entre otras, están en la base de la crisis de acumulación capitalista y representan una clara manifestación del carácter integral del impacto que producen en toda la formación social capitalista. Para comprender integralmente el origen de las políticas estatales en la lógica de la acumulación de capital, es oportuno tener presente la interesante observación que realiza Habermas (1999) en relación con la forma en que el Estado compensa las consecuencias disfuncionales de los procesos de acumulación. Según él, estas se suscitan dentro de ciertas fracciones del capital, en la clase obrera organizada o en grupos capaces de organización, que se manifiestan o se imponen por la vía política ${ }^{12}$.

De acuerdo con el argumento que hemos venido esbozando, las crisis de acumulación capitalista inciden en la articulación orgánica estructura/superestructura y, por lo tanto, en la recomposición de las categorías y las funciones organizativas y conectivas de los(as) intelectuales orgánicos(as). La lógica que le confiera, como respuesta desde el Estado, el grupo fundamental a dicha crisis, definirá un proceso que incidirá y modificará sustancialmente: a) el mercado de trabajo para adaptarlo a la reestructuración del capital; b) las escalas de calificaciones y las ocupacionales que tendrán que ajustarse a los nuevos requerimientos del mercado de trabajo; y como consecuencia de todo lo anterior, c) la respuesta del sistema educativo (función económica, expresada como política educativa del Estado) al mercado de trabajo en materia de formacióncalificación de la fuerza de trabajo.

\footnotetext{
$\overline{12}$ En el conjunto de las compensaciones estatales, expresadas como regulaciones o intervenciones que el Estado realizó ante las presiones de los sindicatos o partidos reformistas para mejorar la situación social de los trabajadores. Habermas establece en orden de aparición histórica: "la lucha por el derecho de asociación; vino después la legislación sobre salarios, condiciones de trabajo y mejoras sociales, hasta llegar a la política educativa, de medios de transporte, sanitaria" (Habermas, 1999, 100). Estas acciones estatales se orientaron hacia los valores de uso y fueron impuestas por medios políticos como respuesta a las exigencias del movimiento obrero organizado.
} 
Según la tesis gramsciana, la génesis del proceso hegemónico está vinculada a la aparición de la actividad educativa en la sociedad modema; por eso, es la resultante de una articulación orgánica entre lo político y lo educativo como parte del proceso de configuración de la formación social capitalista. Este proceso, desde un punto de vista integral, es producto de la modemización en la dimensión de la formación de la sociedad racional. Vale mencionar, de la configuración histórica del capitalismo monopolista y del capitalismo avanzado, que en su complejidad constitutiva, se manifiesta en procesos particulares, tales como: los niveles y grados crecientes de desarrollo de la estructura productiva industrial; el avance tecnológico y la razón instrumental; la aparición de nuevas relaciones y prácticas sociales y la consolidación de la sociedad civil como escenario de la vida social de la nación y de sus ciudadanos; la instauración del Estado modemo (sociedad política) y de su creciente ampliación de su papel y de su aparato institucional (Miranda, 2005); la ampliación cuantitativa y cualitativa de la categoría social de los(as) intelectuales (en virtud de la necesidad histórica de la configuración de la hegemonía social) y las nuevas funciones ideológicas impuestas por las clases dirigentes.

Por esta razón, como se ha mencionado, Gramsci (AP, 1985) asoció el desarrollo educativo y la organización escolar surgidos en las sociedades modemas a las categorías y las funciones intelectuales. Al resaltar la importancia de este proceso, observa que la profundización y ampliación de la intelectualidad de cada individuo y la multiplicación de las especialidades y su perfeccionamiento, son el producto del nivel alcanzado por la organización del sistema escolar: desde las instituciones escolares de diverso grado, hasta las instituciones encargadas de promover la alta cultura en todos los campos de la ciencia y de la técnica. En sus palabras:

La escuela es el instrumento para elaborar a los intelectuales de diferente grado. La complejidad de la función intelectual en los diferentes Estados puede medirse objetivamente por la cantidad de escuelas especializadas y por la jerarquización de las mismas: cuanto más extensa sea el área de la enseñanza y más numerosos los 'grados' 'verticales' de la escuela, tanto más complejo será el mundo cultural, la civilización de un determinado Estado (AP, 1985, 63).

De este pasaje se desprende que el proceso de estructuración del sistema educativo está articulado, en consecuencia, a la estructuración del sistema educativo modemo de acuerdo con la lógica de la hegemonía que las clases dirigentes promueven desde el Estado. Desde esta visión, el Estado asume como 
una de sus funciones producir un consenso a través de formas selectivas de conocimiento social, puesto a disposición y de la configuración de la práctica ideológica (Sharp, 1988). Como se ha explicado, la estrategia de estructuración del sistema educativo, como función estatal, obedece a una acción que se define por la necesidad de conferirle un carácter orgánico y una direccionalidad al sistema productivo acorde con sus intereses y, al mismo tiempo, al logro no sólo de los objetivos políticos y culturales, sino también los económicos del programa político promovido por las clases dirigentes.

Para el logro de estos objetivos políticos contenidos en su programa político y económico, la clase dirigente realiza, desde el punto de vista de la relación orgánica de la base estructura/superestructura, una acción de política educativa tendiente a la preparación de los(as) intelectuales y la organización del sistema educativo en todos sus niveles. Gramsci apunta que no puede separarse la relación calidad/cantidad en la preparación de los(as) intelectuales en las escuelas dedicadas a esa preparación; además, aclara que en este aspecto son asimilables también las escuelas y los institutos de alta cultura.

El punto neurálgico de esta cuestión consiste, en el sistema conceptual de Gramsci, en que la política educativa que se impulsa desde el Estado posibilite una correspondencia de la relación calidad/cantidad desde la primaria hasta " $l a$ más refinada especialización técnico-cultural”. Al respecto, menciona que:

(...) esta necesidad de crear una base lo más amplia posible para la selección y la elaboración de las cualificaciones intelectuales más altas - es decir, de darle a la alta cultura y a la técnica superior una estructura democrática-no deja de tener inconvenientes: se crea así la posibilidad de dilatadas crisis de desocupación de las capas medias de intelectuales, como ocurre de hecho en todas las sociedades modermas (AP, 1985, 63).

En este pasaje alude nuevamente a uno de los problemas fundamentales del mundo capitalista moderno y que ha sido una constante en el proceso histórico de configuración del capitalismo avanzado: la creación del ejército laboral de reserva, como estrategia de control de los salarios y del mercado laboral competitivo, y sus consecuentes problemas de desempleo en contextos de crisis económicas.

\section{LA POLÍTICA EDUCATIVA COMO PROCESO HEGEMÓNICO}

La posición gramsciana de hegemonía parte de que el poder político, como dominio de las clases dirigentes, no es una condición suficiente para conservar 
la unidad de la sociedad, sino que es necesario el establecimiento de un consenso obtenido a través de la dirección ideológica. La hegemonía comprende, como bien lo destaca Eagleton $(1997,153)$, una compleja variedad de estrategias políticas que la clase dirigente utiliza para obtener el consentimiento de aquellas personas a las que domina. Desde esta visión, la hegemonía se orienta a establecer pautas morales, sociales e intelectuales en la vida social para imponer su propia "concepción del mundo" a todos los sujetos sociales y organizaciones que integran el entramado de la sociedad civil, como si fueran los suyos propios. En consecuencia, la búsqueda del consenso se torna en el centro de las estrategias políticas independientemente de la forma de poder político que impere en el escenario social, la norma consensual no es sólo característica del capitalismo.

Es indispensable, por lo tanto', la obtención de una hegemonía ideológica como condición indispensable para el mantenimiento del poder (en cualquier sistema político). En este aspecto radica la existencia de los dos momentos. Por un lado, el de la superestructura del Estado y de la política (sociedad política) y, por otro, el de la sociedad civil: campo de la hegemonía y de la acción orientada ideológicamente en la transmisión y dirección del consenso a través de los medios e instrumentos especializados, donde la escuela ocupa un lugar primordial.

La importancia capital de la noción de hegemonía radica, asimismo, en la riqueza de sus implicaciones culturales y políticas que Gramsci asigna al bloque histórico. Coincidimos con la apreciación que realiza Eagleton cuando manifiesta que el concepto de hegemonía amplía y enriquece la noción de ideología asignándole, además, a este concepto abstracto una dimensión material y una vertiente política; en esta perspectiva, señala que con Gramsci tu vo lugar una transición crucial de la ideología como sistema de ideas a ideología como una práctica social auténtica y habitual, que abarca supuestamente "las dimensiones inconscientes y no articuladas de la experiencia social además del funcionamiento de las instituciones formales" (1997, 152-153). Es en esta dimensión donde se sitúa el problema pedagógico según Broccoli:

El hecho es que la concepción gramsciana de la relación pedagógica en sentido estricto, gira en torno a tres términos -hombre, maestro, ambiente-entendidos como procesos históricos autónomos, y sin embargo correlacionados, que se realizan en una nueva unidad llamada bloque histórico, por la mediación de la intervención hegemónica. Y aún esta nueva unidad es en sí un proceso destinado a modificarse y a crearse de continuo configuraciones internas apropiadas (1977, 156-157). 
Esta delimitación contextual del proceso pedagógico es la que posibilita apreciar la doble dimensión de la hegemonía como proceso educativo, que se realiza tanto en la esfera total de la sociedad como en el ámbito escolar: el ambiente en el que tiene lugar la relación pedagógica educador(a)-alumno(a). Por esta razón, la visión gramsciana de la hegemonía, a partir de esa doble dimensión, corresponde a un proceso unitario que concibe la relación educativa como expresión de la interacción dialéctica sociedad/educación.

La naturaleza dialéctica, la interacción entre la educación y la sociedad en su conjunto, provoca una dinámica de profundos cambios recíprocos. Asimismo, una comprensión de la forma en que se manifiesta y opera la relación educativa requiere, desde un punto de vista heurístico, realizar un análisis interpretativo de los principales fundamentos a partir de los cuales la educación se desenvuelve en la dinámica política y cultural de la sociedad civil. Esto es, analizar e interpretar la interacción dialéctica entre sus estructuras social y económica, y la producción, reproducción y el control de su sistema ideológico (como marco de representaciones simbólicas), en aras de la unidad social y cultural. En un sentido genérico, la escuela está concebida desde una visión gramsciana como un conjunto cultural (Portelli, 1980). En consecuencia, el proceso hegemónico educativo se realiza en dos ámbitos: el ámbito general de la sociedad civil donde despliega su influjo educativo el sistema escolar y, como parte de él, el ámbito particular, el escenario donde tiene lugar la relación pedagógica, es decir, donde se da la interacción dialéctica hombre/maestro/ambiente: la institución educativa y su entorno sociocultural.

En la tesis referente al proceso hegemónico educativo, Gramsci (AP, 1985, 51-52) plantea que el "problema del logro de una unidad cultural-social sobre la base de una común y general concepción del mundo", podía y debía asimilarse al "planteamiento moderno de la doctrina y de la práctica pedagógica", según la cual la relación pedagógica entre maestro(a) y alumno(a) es dinámica y de vínculos recíprocos, "por lo que todo maestro sigue siendo alumno y todo alumno es maestro”. Asimismo, afirma que la relación pedagógica no se circunscribe sólo a las relaciones específicamente "escolares", mediante las cuales la interacción entre las viejas generaciones y las nuevas hace que estas absorban "las experiencias y valores históricos necesarios madurando y desarrollando una propia personalidad histórica y culturalmente superior". Además, expresa que esta relación se efectúa en la sociedad en su conjunto, en cada individuo respecto de los demás, entre castas intelectuales y no intelectuales, entre gobernantes y gobernados, entre dirigentes y dirigidos. Por último, concluye que "toda relación de hegemonía es necesariamente pedagógica", y se escenifica no sólo dentro de la nación entre las diferentes fuerzas 
que la integran, sino en "el campo internacional y mundial, entre conjuntos de civilizaciones nacionales y continentales".

El carácter comprehensivo de esta tesis reviste particular importancia, porque posibilita dimensionar las funciones modernas que asume la educación en el contexto del proceso hegemónico, que impulsan en la actualidad las clases dirigentes desde el Estado, en los planos social, económico y cultural. Su delimitación e interpretación teórica en el marco del proceso sociohistórico de configuración de la modernidad y su delimitación e interpretación contextual en la obra gramsciana, hacen posible comprender como se articulan las funciones educativas. Señala Sharp, a las "relaciones específicas de dominación y subordinación que están relacionadas con la distribución del poder" $(1988,95)$.

La tesis gramsciana sobre el proceso hegemónico educativo recoge sintéticamente, teniendo en cuenta las consideraciones analíticas precedentes, la configuración de las funciones modernas de la educación y del papel del sistema escolar moderno, articulados a la dinámica de la producción capitalista y la lógica de la hegemonía política y cultural que impulsan las clases dirigentes. Por lo tanto, como proceso, tiene lugar en el espacio en que se realizan las funciones de la educación en la sociedad civil: en la cual se desarrollan las relaciones culturales e ideológicas, por medio de la hegemonía que las clases dirigentes mantienen en virtud de su liderazgo cultural, intelectual y político sobre toda la sociedad.

La teoría gramsciana de los intelectuales, como educadores y persuasores, cuya acción se dirige al establecimiento del consenso del programa político-económico de la clase fundamental, está relacionada con la configuración del proceso hegemónico, especialmente de aquellas personas que asumen las funciones educativas. A ellas les corresponde formular y renovar, a partir de la concepción filosófica integradora del sistema ideológico, el sistema de valores y de creencias: el marco de representaciones simbólicas que fundamenta el bloque histórico; de ahí que asuman la función de organizar el consenso en la población en la dirección establecida por la clase fundamental. En este aspecto es importante recalcar que las concepciones pedagógicas, las teorías del aprendizaje, los enfoques curriculares y didácticos que integran la política educativa, devienen en elementos de mediación en las relaciones educativas que operan en la sociedad civil, a través del sistema escolar. Ese carácter mediador les viene conferido por la orientación político-ideológica en que se fundamenta el programa político, es decir, la dirección que el grupo dominante fundamental le pretende otorgar a la vida social.

Como una dimensión singular de la hegemonía que ejercen las clases dirigentes sobre las clases subordinadas, el proceso hegemónico educativo 
representa el momento histórico en que el avance de la modernización capitalista hace surgir la función sociopolítica de la educación, como una dimensión particular de la estatización de la sociedad civil. Es el momento histórico en que el Estado asume, en el conjunto de sus acciones, la función política de la educación, dando lugar a una articulación sistemática entre las funciones políticas y las educativas. En consecuencia, en virtud de esa articulación de carácter orgánico, nace la concepción moderna de política educativa.

Este proceso se genera en el capitalismo liberal como una dimensión del incipiente papel intervencionista del Estado y la formación del sector público y, por consiguiente, está vinculado a las transformaciones estructurales del desarrollo capitalista, entre cuyas claves más significativas están: a) la necesidad de favorecer la reproducción de un sistema institucionalmente cada vez más complejo, en el que el capital se muestra débil e ineficiente para asegurar sus exigencias reproductivas; b) la internacionalización del capital y la creciente pugna por los mercados internacionales, derivadas de los monopolios y las dificultades de acumulación que enfrentaba el desarrollo del capital; c) el creciente costo de producción e implantación de las tecnologías en el proceso productivo; d) la necesidad y creciente complejidad de producción de la fuerza de trabajo; y e) el imperativo de introducir factores legitimadores y estabilizadores del sistema capitalista (Moral y Raimond, 1986, 14).

Portelli destaca las razones que originan el proceso de estatización:

$1^{\circ}$ Necesidad de un control por parte del Estado para elevar el nivel técnico-cultural de la población respondiendo así a las exigencias del desarrollo de las fuerzas productivas; $2^{\circ}$ conflicto entre los intelectuales tradicionales (especialmente la Iglesia, resto del antiguo bloque histórico, y los intelectuales de la clase dominante); y $3^{\circ}$ necesidad de unificar la ideología difundida por las organizaciones de la sociedad civil $(1980,33)^{13}$.

El establecimiento de una unidad cultural y social es el elemento integrador del proceso hegemónico en todas sus dimensiones. Ello conduce a que la orientación de ese proceso se enmarque en una filosofía, como expresión superior del sistema ideológico y como expresión cultural de la clase fundamental. En su condición de ser la referencia de todo el sistema ideológico, es la "piedra angular de la ideología” y, por lo tanto, piedra angular de la hegemonía que

\footnotetext{
${ }^{13}$ Podría añadirse como consideración adicional la tesis de Althusser de que el Estado a través del sistema escolar (en su denominación "aparatoideológicoescolar") ejerce la función de reproducción de las relaciones sociales de producción, y específicamente de la fuerza de trabajo.
} 
posee el máximo de coherencia y comprende las normas de vida de todas las capas sociales (Portelli, 1980). Es, precisamente, la condición de legitimidad que adquiere la ideología y a la que se adhirió la educación, como parte de la lógica racional establecida en el proceso de consolidación de la modernidad capitalista, que analizamos en otro momento (Miranda, 2005). En consecuencia, la ideología obtiene legitimidad recurriendo al expediente de universalizarse o etemizarse, presentando los valores e intereses de la clase dirigente como si fueran de todos los miembros de la sociedad.

Además, la dimensión cultural de esta tesis pone de manifiesto el carácter intergeneracional de la educación, que la clase dirigente promueve para asegurar la permanencia de su cultura y su visión de mundo: la continuidad de la unidad social y cultural. Esto apunta al carácter cultural del proceso hegemónico educativo, siendo la intención de la clase dirigente asegurar esa continuidad histórica del control sobre la difusión de la cultura a través del principal agente: el sistema educativo. El papel de mediación política, que subyace a las relaciones pedagógicas, mediatizado por un discurso pedagógico y las intenciones que existen en esas formulaciones pedagógicas, están en la base del carácter totalizador del proceso hegemónico educativo. De esta manera, se constituyen en los elementos ideológicos vertebradores de la política educativa, tanto en su formulación de los fines educacionales, las teorías pedagógicas, los enfoques curriculares, la evaluación y las metodologías didácticas, como en los procesos educativos que tienen lugar en las instituciones del sistema escolar.

Al dimensionar toda relación de hegemonía como pedagógica, Gramsci le confiere un carácter totalizador al proceso pedagógico, por cuanto lo concibe como una acción que irradia al conjunto de la sociedad global. Este proceso, en consecuencia, abarca la relación de los individuos con los demás, las clases sociales fundamentales, sus fracciones y todos los grupos sociales, las prácticas sociales, los cambios estructurales en el sistema económico, la vida cultural, etc. Al mismo tiempo, ese carácter totalizador se manifiesta como un elemento central, que la clase dirigente le confiere al proceso hegemónicoeducativo en la búsqueda del consenso que posibilite un apoyo social de base a su programa político y económico. Así, la política educativa surge vinculada a una estrategia de legitimación y reproducción general del sistema capitalista. Es importante poner de relieve, asimismo, que la hegemonía en la relación educativa prefigura, según la tesis gramsciana, las siguientes dimensiones: el papel destinado a desempeñar por la educación en el contexto internacional, como expresión de los objetivos de un proceso hegemónico que trasciende las fronteras nacionales, que es el caso de la mundialización (dimensión esencial de la globalización neoliberal); y el papel en el ámbito internacional, en materia educativa, de los organismos internacionales. 


\section{REFERENCIAS}

\section{Siglas de la obra de Gramsci}

AP (1985). La alternativa pedagógica. Barcelona, Hogar del Libro.

IO (1975). Los intelectuales y la organización de la cultura. México, Juan Pablos Editor.

MS (1975). El materialismo histórico y la filosofía de B. Croce. México, Juan Pablos Editor.

PP (1975). Pasado y presente. México, Juan Pablos Editor.

\section{Bibliografía general}

Belligni, S. (1982). "Hegemonía”. En Bobbio, N. y Matteuci, N. Diccionario de política. Madrid, Siglo Veintiuno.

Bobbio, N. (1980). Gramsci y la concepción de la sociedad civil. Barcelona, Avance. (1982). "Sociedad civil". En Bobbio, N. y Matteuci, N. Diccionario de política. Madrid, Siglo Veintiuno.

Broccoli, A. (1977). Antonio Gramsci y la educación como hegemonía. México, Editorial Nueva Imagen.

Dubiel, H. (1993). ¿Qué es neoconservadurismo? Barcelona, Editorial Anthropos.

Eagleton, T. (1997). Ideología. Una introducción. Barcelona, Paidós.

Eccleshall, R. (1993). “Conservadurismo”. En VV.AA. Ideologías políticas. Madrid, Tecnos.

Femia, J.W. (1987). Gramsci's political thought: hegemony, consciousness and revolutionary process. Oxford, Claredom Press.

Femández, F. (2001). Leyendo a Gramsci. España, El Viejo Topo.

García, E. (1991). "Reforma escolar, acumulación, legitimación y Estado del bienestar”. En VV.AA. Sociedad, cultura y educación. Madrid, CIDE-Universidad Complutense de Madrid.

Habermas, J. (1999). Problemas de legitimación en el capitalismo tardio. Madrid, Ediciones Cátedra.

Macciocchi, M.A. (1980). Gramsci y la revolución de Occidente. México, Siglo Veintiuno.

Manacorda, M.A. (1987). Historia de la Educación 2. Del 1500 a nuestros días. México, Siglo Veintiuno.

Matteuci, N. (1982). "Liberalismo". En Bobbio, N. y Matteuci, N. Diccionario de política. Madrid, Siglo Veintiuno.

Miranda, G. (2004). "Capitalismo global y cambio educativo. Los fundamentos estructurales e ideológicos de la política educativa neoliberal". En Revista EDUCARE, Vol. 6. No. 1, 13-42. Universidad Nacional, Heredia. Costa Rica. 
(2005). "Sociedad racional y educación. La génesis de la racionalidad educativa modemista". En Revista EDUCARE, Vol. VIII. No. 1, pp. 11-42. Universidad Nacional, Heredia. Costa Rica.

Moral Santín, J.A. y Raimond, H. (1986). La acumulación del capital y sus crisis. Madrid, Akal.

Portelli, H. (1980). Gramsci y el bloque histórico. México, Siglo XXI.

Ransom, P. (1992). Antonio Gramsci: a new introduction. New York, Harvester Whetsheaf.

Sharp, R. (1988). Conocimiento, ideología y política educativa. Madrid, Akal. 